\title{
Incidence of postoperative nausea and vomiting is not increased by combination of low concentration sevoflurane and propofol compared with propofol alone in patients undergoing laparoscopic gynecological surgery
}

Yuka Uchinami i D, Satoshi Takikawa, Fumiki Takashima, Yosuke Maeda, Satoki Nasu, Ayumi Ito and Tatushi Saito

\begin{abstract}
Background: The incidence of postoperative nausea and vomiting (PONV) is higher in patients receiving volatile anesthetics than those receiving total intravenous anesthesia (TIVA) with propofol. However, it is unclear whether its incidence is increased when a low concentration of sevoflurane is used in combination with propofol.

Methods: This prospective, randomized, controlled trial enrolled women undergoing laparoscopic gynecological surgery. Patients were randomly assigned to receive general anesthesia either with propofol alone (group P) or with $0.8 \%$ sevoflurane and propofol (group SP, $n=36$, each group) for maintenance of anesthesia. The incidence of PONV and the number of patients who required antiemetics were compared.
\end{abstract}

Results: There were no differences in the incidence of PONV and the number of patients who required antiemetics between the P and SP groups.

Conclusions: A combination of $0.8 \%$ sevoflurane and propofol to maintain anesthesia does not increase the incidence of PONV compared with TIVA with propofol.

Trial registration: UMIN-CTR UMIN000023647, registered 14 August 2016.

Keywords: Postoperative nausea and vomiting, Propofol, Sevoflurane, Sevoflurane propofol combination

\section{Background}

Postoperative nausea and vomiting (PONV) is one of the most common adverse effects of anesthesia and is experienced by $25-30 \%$ of patients [1]. This affects the recovery process and patient satisfaction following surgery $[2,3]$. Several factors, including the patient characteristics (sex, smoking status, history of motion sickness or PONV), anesthetic technique employed, and the type of surgery performed, are known to increase the risk of PONV. Total intravenous anesthesia (TIVA) is one method that can be

\footnotetext{
* Correspondence: yukauma923@gmail.com

Department of Anesthesiology, Hakodate Central General Hospital, 3-2, Honcho3, Hakodate 040-8585, Japan
}

used to reduce the incidence of PONV compared to inhalational anesthesia [4-8].

The coadministration of propofol with sevoflurane to maintain anesthesia has been suggested recently $[9,10]$ due to the antiemetic effect of propofol [11], the myocardial protective effects of sevoflurane [12,13], and the possibility of smooth emergence from anesthesia. It has also been demonstrated that the coadministration of sevoflurane and propofol to maintain anesthesia reduces the incidence of PONV compared with sevoflurane alone $[14,15]$. Therefore, propofol with sevoflurane to maintain anesthesia could provide an easy-to-use alternative to using TIVA for people at risk of developing PONV. However, the incidence of PONV using propofol in 
combination with inhalational anesthesia compared to using TIVA is not known. Therefore, the aim of this study was to compare the incidence of PONV between general anesthesia with propofol alone and propofol in combination with sevoflurane.

\section{Methods}

The study was a prospective, randomized, observerblinded, interventional, single-center trial, conducted in accordance with the current Declaration of Helsinki. Ethics approval was obtained from the institutional review board of the Hakodate Central Hospital, Hakodate, Japan (April 22, 2016, No. 2016-2). This trial was registered with the UMIN Clinical Trial Registry (UMIN 000023647).

Between August 2016 and February 2017, we enrolled 88 consecutive patients aged 20-60 years, who were scheduled to undergo elective laparoscopic gynecological surgery under combined general/epidural anesthesia. Written informed consent was obtained from all the patients before randomization. The exclusion criteria were patients with ASA physical status $\geq$ III, with pregnancy or cognitive dysfunction. Patients for whom surgical procedure was changed to laparotomy, epidural anesthesia was ineffective, or follow-up data were lost were also excluded.

After providing patients with an explanation of this study, to evaluate the PONV risk score, patients were asked three questions to ascertain whether they had a history of smoking, motion sickness, or PONV [14]. An affirmative answer for each question was scored 1 point. Subsequently, patients were randomly assigned to two groups using computer-generated random numbers (JMP, version 12.0.1; SAS Institute, Cary, NC, USA). The patient allocation was revealed to each anesthesiologist via a sealed envelope on the day of the surgery. The surgeons, anesthesiologists, statistical analysts, and medical staff in the operating room were not blinded to the treatment group, while the patients, ward staff, and observers were blinded.

No preoperative sedatives or analgesics were administered. After placing the peripheral vein and epidural catheters at the Th12/L1 level, an electrocardiogram, pulse oximetry, noninvasive arterial pressure, muscle relaxant, and end-tidal $\mathrm{CO}_{2}\left(\mathrm{EtCO}_{2}\right)$ monitors were used. Propofol was administrated via a target-controlled infusion (TCI) device (Cardinal Health, Basingstoke, UK), using a threecompartment model that was proposed by Schnider et al. [15]. Anesthesia induction was performed using propofol TCI $(3-5 \mu \mathrm{g} / \mathrm{ml})$, remifentanil $(0.1-0.5 \mu \mathrm{g} / \mathrm{kg} / \mathrm{min})$, fentanyl $(0.2-2 \mu \mathrm{g} / \mathrm{kg})$, and rocuronium $(0.6-0.9 \mathrm{mg} / \mathrm{kg})$. Following tracheal intubation, the lungs were ventilated so as to maintain $\mathrm{EtCO}_{2}$ between 35 and $45 \mathrm{mmHg}$ in $50 \%$ oxygen at a total flow of $1 \mathrm{~L} / \mathrm{min}$. Patients received either propofol alone (group P) or $0.8 \%$ sevoflurane and propofol (group SP) for maintenance of anesthesia. In addition to propofol with an infusion rate adjusted to maintain bispectral index (BIS; A-2000TM SP, Aspect Medical System, Norwood, MA, USA) between 40 and 60, i.v. remifentanil $0.05-0.25 \mathrm{~g} / \mathrm{kg} / \mathrm{min}$ and epidural ropivacaine $(0.75 \%, 4-5$ $\mathrm{ml} / \mathrm{h}$ ) were administered to all patients. Fentanyl, antiemetics, or nonsteroidal anti-inflammatory drugs were not administered during surgery. Rocuronium $10 \mathrm{mg}$ was administered when train-of-four (TOF) count was $>1$. Hypotension (MAP $<60 \mathrm{mmHg}$ ) was treated with intravenous phenylephrine or ephedrine.

The administration of propofol, remifentanil, and sevoflurane was stopped upon completion of the surgery. Sugammadex $2 \mathrm{mg} / \mathrm{kg}$ (when the TOF count was $\geq 2$ ) or $4 \mathrm{mg} / \mathrm{kg}$ (when the TOF count was $\leq 1$ ) was administered. Subsequently, patients were observed without being awoken until they naturally aroused. Tracheal extubation was performed when spontaneous breathing recovered sufficiently with a TOF count of $>0.9$, and the patients were able to follow verbal commands.

After operation, $4 \mathrm{ml} / \mathrm{h}$ of $0.25 \%$ levobupivacaine was administrated via an epidural catheter for postoperative analgesia. Pain assessment was conducted by ward nurses every $3 \mathrm{~h}$, and flurbiprofen or acetaminophen was administered for additional analgesia.

The primary outcome of this study was the incidence of PONV. We also scored the severity of the PONV $(0=$ no nausea, $1=$ mild nausea recovered without antiemetics, $2=$ severe nausea requiring antiemetics, and $3=$ retching, vomiting, or both) every $3 \mathrm{~h}$ until up to $12 \mathrm{~h}$ post-surgery and then evaluated the maximum PONV score. We defined patients with a PONV risk score of 1 or less as low risk, and a PONV risk score of 2 or more as high risk, which was used to evaluate the max PONV score. Other factors that were evaluated included the following: level of agitation evaluated using the Ricker sedation scale (1-7 points); amount of coughing at two time points, immediately after extubation and on leaving the operation room [16]; pain scale $(0-10)$ [17]; scores assigned to the quality of recovery assessed via a questionnaire [18]; and perioperative patient satisfaction scores $(1=$ very unsatisfied, $2=$ somewhat unsatisfied, $3=$ not satisfied or unsatisfied, $4=$ somewhat satisfied, and $5=$ very satisfied). These were recorded $24-30 \mathrm{~h}$ following the day of surgery.

The sample size was calculated by power analysis while designing the study. We included independent cases and controls, with 1 control per case. A previous study [19] indicated that the incidence of PONV after TIVA was 0.125 and that when using an inhalation agent was 0.415 . On applying these results to the sample size calculation, a total of 36 experimental and 36 control subjects were required to reject the null hypothesis, and such that the failure rates for experimental and control subjects are equal with a power of 0.8 . The probability 
of type I error associated with the testing of this null hypothesis was 0.05 with an uncorrected chi-squared test (PS: Power and Sample Size Calculation version 3.1.2, 2014, Vanderbilt University, Nashville, TN, USA).

The values were either expressed as median (interquartile range $[\mathrm{IQR}]$ ) or by percentage of patients (\%). Statistical analyses were performed using commercially available software (JMP, version 12.0.1; SAS Institute, Cary, NC, USA). An independent $t$ test was used to analyze parametric data, and nonparametric data were analyzed by the Mann-Whitney $U$ test. Categorical variables were evaluated by the Fisher exact test. $P<0.05$ was considered statistically significant.

\section{Results}

Among 88 patients eligible for this study, 11 were excluded (2, ASA-PS III; 1, pregnant; 8, did not provide consent). Consequently, 77 patients were randomized and received the intervention. Following this, two patients were excluded because they did not complete the interview form, and three patients were excluded because they were transitioned to open surgery. Eventually, the remaining 36 patients in each group successfully completed the study protocol (Fig. 1). Table 1 shows the demographic data of patients. Patients' profiles, PONV risk score, and the type of surgery were similar between the two groups. There were no differences in the incidence of PONV (27.8\% and $33.3 \%$ in the groups P and SP, respectively) (Fig. 2) and the total PONV score (0 $[0-1]$ vs 0 [0-2]; median [interquartile range]) between the two groups. The number of patients who required antiemetics was also not different between the two groups (Table 2). The total doses of rocuronium, fentanyl, and infusion fluid volume were significantly higher in group P than in group SP. No significant differences were recorded between the groups in the pain experienced at the wound site (mainly umbilical site) (median 6, IQR 3-8 vs. median 5, IQR 4-7.75; $P=$ 0.685 ); however, the shoulder pain was significantly more intense in group $\mathrm{P}$ than in group SP (median 2.5, IQR $0-5.75$ vs. median 0 , IQR $0-4 ; P=0.047$ ) (Table 2).

\section{Discussion}

We have shown that sevoflurane/propofol combination did not increase the incidence of PONV compared with propofol alone. Liang et al. [20] showed no differences in the use of postoperative antiemetics between patients receiving the combination of sevoflurane/propofol and sevoflurane alone. On the other hand, Kawano et al. [21] showed a lower incidence of PONV in those receiving the sevoflurane/propofol combination than those receiving sevoflurane alone, suggesting the antiemetic effect of propofol. However, there have been no studies comparing the sevoflurane/propofol combination and propofol alone on the development of PONV.

Present findings would result from the antiemetic effect of propofol and low concentration of sevoflurane $(0.8 \%)$ used with propofol for maintaining the depth of anesthesia compared with sevoflurane alone. Gan et al. [22] found that the plasma propofol concentration associated with a $50 \%$ decrease in nausea scores was $343 \mathrm{ng} /$ $\mathrm{ml}$. In the present study, average plasma concentration of propofol was $1.2 \mu \mathrm{g} / \mathrm{ml}$ in patients receiving the combination of propofol/sevoflurane and it requires approximately $30 \mathrm{~min}$ to decrease its plasma concentration below $343 \mathrm{ng} / \mathrm{ml}$, suggesting that propofol may have

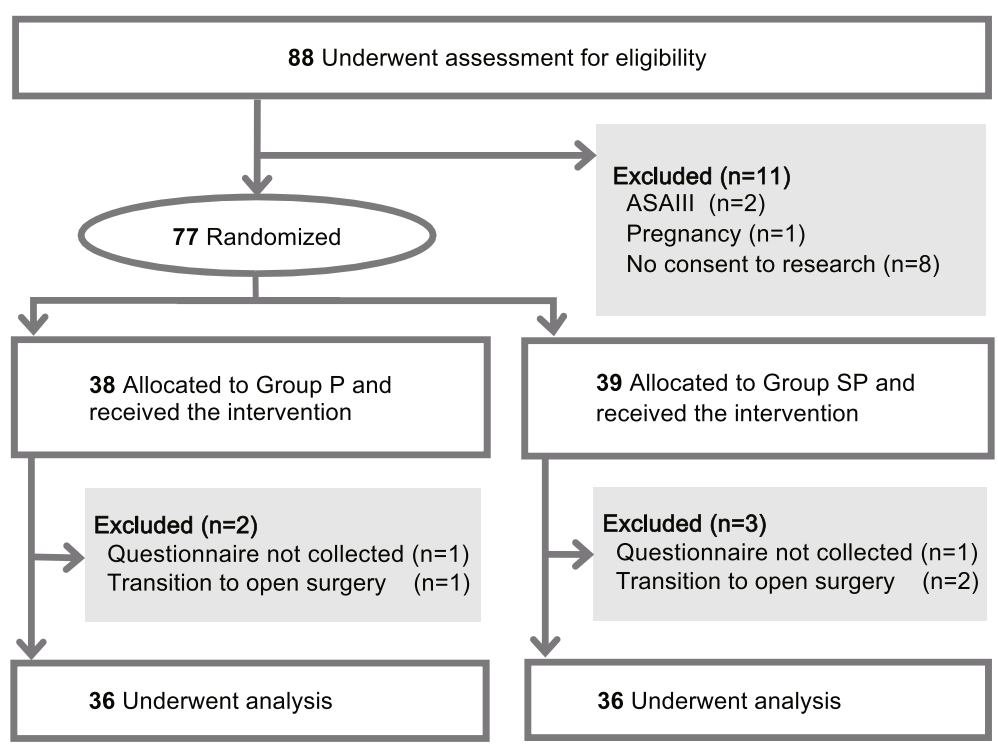

Fig. 1 Flow diagram of patients enrolled in the study 
Table 1 Demographic data of patients enrolled in the study

\begin{tabular}{llll}
\hline Characteristic & $\begin{array}{l}\text { Group P } \\
{[N=36]}\end{array}$ & $\begin{array}{l}\text { Group SP } \\
{[N=36]}\end{array}$ & $P$ value \\
\hline Age (years) & $41.8 \pm 8.0$ & $40.0 \pm 8.7$ & 0.24 \\
Height (cm) & $158.7 \pm 5.5$ & $157.8 \pm 6.2$ & 0.80 \\
Weight (kg) & $56.3 \pm 7.7$ & $57.4 \pm 10.2$ & 0.92 \\
BMI (kg/m $\left.{ }^{2}\right)$ & $22.4 \pm 3.3$ & $23.0 \pm 3.6$ & 0.51 \\
ASA class [ $(\%)]$ & & & \\
I & $20(55.6 \%)$ & $19(52.8 \%)$ & 1.00 \\
II & $16(44.4 \%)$ & $17(47.2 \%)$ & \\
PONV risk score & $1.1 \pm 0.6$ & $1.1 \pm 0.7$ & 0.70 \\
Type of surgery ( $n)$ & & & \\
Ovarian cystectomy/tumorectomy & 7 & 17 & 0.089 \\
Oophorectomy & 1 & 1 & \\
Myomectomy & 8 & 5 & \\
Endometriosis lesion removal & 2 & 2 & \\
Tubalectomy & 1 & 0 & \\
Hysterectomy & 16 & 8 & \\
Adhesion exfoliation & 1 & 3 &
\end{tabular}

Data are presented as mean \pm SD or the number of patients and frequency (\%). Anesthesia was maintained with propofol (group P) and with a combination of sevoflurane and propofol (group SP)

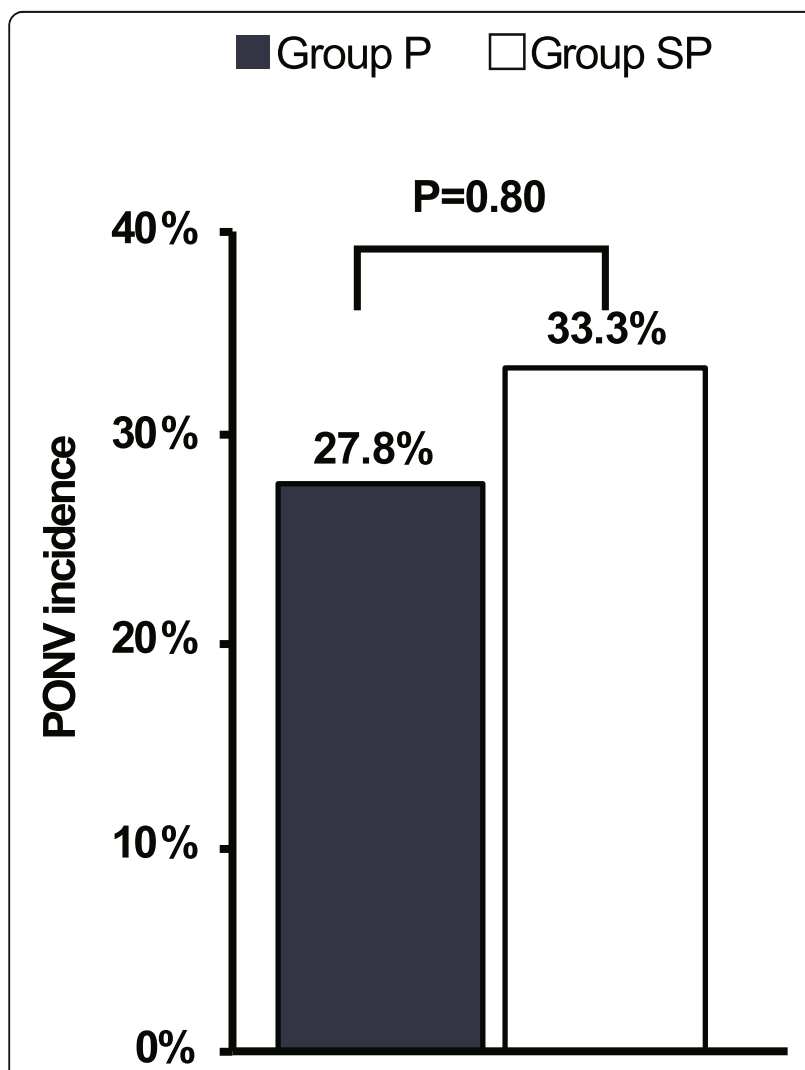

Fig. 2 Incidence of postoperative nausea and vomiting. Anesthesia was maintained with propofol (group P) and with a combination of sevoflurane and propofol (group SP)
Table 2 Anesthesia-related parameters and recovery profiles

\begin{tabular}{|c|c|c|c|}
\hline Characteristic & $\begin{array}{l}\text { Group P } \\
{[N=36]}\end{array}$ & $\begin{array}{l}\text { Group SP } \\
{[N=36]}\end{array}$ & $P$ value \\
\hline $\begin{array}{l}\text { Duration of surgery } \\
\text { (min) }\end{array}$ & $\begin{array}{l}155 \\
(110.5,194.5)\end{array}$ & $\begin{array}{l}120 \\
(86.5,219.7)\end{array}$ & 0.13 \\
\hline $\begin{array}{l}\text { Total dose of } \\
\text { rocuronium (mg) }\end{array}$ & $\begin{array}{l}100 \\
(70,163)\end{array}$ & $\begin{array}{l}80 \\
(60,97.5)\end{array}$ & 0.029 \\
\hline $\begin{array}{l}\text { Dose of fentanyl } \\
(\mu \mathrm{g})\end{array}$ & $25(25,50)$ & $25(25.25)$ & 0.0078 \\
\hline $\begin{array}{l}\text { Dose of remifentanil } \\
\text { per hour }(\mathrm{mg} / \mathrm{h})\end{array}$ & $\begin{array}{l}0.0083 \\
(0.0077,0.013)\end{array}$ & $\begin{array}{l}0.0092 \\
(0.0071,0.012)\end{array}$ & 0.78 \\
\hline Blood loss (ml) & $67.5(10,145)$ & $50(10,75)$ & 0.10 \\
\hline Fluid volume (ml) & $\begin{array}{l}700 \\
(512.5,1012.5)\end{array}$ & $\begin{array}{l}450 \\
(312.5,550)\end{array}$ & $<0.001$ \\
\hline $\begin{array}{l}\text { Usage of antiemetics } \\
(\%)\end{array}$ & $8(22.2)$ & $8(22.2)$ & 1.00 \\
\hline $\begin{array}{l}\text { Time to extubation } \\
\text { (min) }\end{array}$ & $10(6,12)$ & $9(7,11)$ & 0.37 \\
\hline $\begin{array}{l}\text { Aroused excitement } \\
\text { score }\end{array}$ & $4(3,4)$ & $4(3,4)$ & 0.56 \\
\hline Cough score & $0(0,0)$ & $0(0,1)$ & 0.31 \\
\hline $\begin{array}{l}\text { The quality of } \\
\text { recovery score }\end{array}$ & $14(11,15)$ & $13(11,15)$ & 0.39 \\
\hline Satisfaction score & $3(2,4)$ & $3(2,4)$ & 0.72 \\
\hline $\begin{array}{l}\text { NRS score of } \\
\text { wound } \\
\text { sight }\end{array}$ & $6(3,8)$ & $5(4,7.75)$ & 0.68 \\
\hline $\begin{array}{l}\text { NRS score of } \\
\text { shoulderpain }\end{array}$ & $2.5(0,5.75)$ & $0(0,4)$ & 0.030 \\
\hline
\end{tabular}

Data are presented as median (IQR) or the number of patients and frequency (\%). Anesthesia was maintained with propofol (Group P) and with a combination of sevoflurane and propofol (Group SP)

effectively prevented the early stage of PONV. The differences in the dose of fentanyl and fluid volume would not have influenced the incidence of PONV between those two groups of patients.

There were no significant differences in the level of wound pain; in contrast, patients receiving propofol only reported a higher numerical rating scale for shoulder pain. Although the reason is not clear, lower neuromuscular blocking effect of propofol than sevoflurane might account for this because deeper neuromuscular blockades reduce shoulder-tip pain following laparoscopic surgery [23]. Future studies are required to confirm this hypothesis.

There are several limitations to our study. First, we did not administer PONV prophylaxis. This was because we tried to investigate the baseline risk, which could have been masked by prophylactic antiemetics. Especially in the case of high-risk patients, further studies are necessary to compare the results when antiemetics are used. Second, the study subjects were limited only to women. Our aim was to conduct research on relatively high PONV risk patients who were undergoing laparoscopic 
surgeries and were young women; therefore, it is unclear whether this result can be applied to other patient groups. Third, only one combination of propofol infusion rate and sevoflurane concentration was studied, and the effects of other combinations were not assessed. Therefore, the optimal combination of the propofol infusion rate and sevoflurane concentration remains to be determined.

\section{Conclusion}

In conclusion, general anesthesia maintenance with the coadministration of sevoflurane and propofol does not increase PONV compared to TIVA and, therefore, can be one of the useful methods to maintain general anesthesia. Further studies are needed to show the effectiveness of propofol/sevoflurane combination anesthesia.

\section{Abbreviations \\ $\mathrm{EtCO}_{2}$ : End-tidal $\mathrm{CO}_{2}$; NRS: Numerical; PONV: Postoperative nausea and vomiting; TCl: Target-controlled infusion; TIVA: Total intravenous anesthesia; TOF: Train-of-four}

\section{Acknowledgements}

We thank Prof. Yuji Morimoto, Hokkaido Univ., for the review and critique of the manuscript.

We also thank the gynecologists for the cases at Hakodate Central Hospital, Hakodate, Japan.

\section{Authors' contributions}

FT, YM, SN, and Al collected the data and drafted the manuscript. ST and TS revised the manuscript. All authors read and approved the final manuscript.

\section{Funding}

The author received no specific funding for this work.

\section{Availability of data and materials}

This is available as an electronic file upon request.

\section{Ethics approval and consent to participate}

The study was approved by the institutional review board of the Hakodate Central Hospital, Hakodate, Japan (approval number: 2016-2). Written informed consent was obtained from all the patients.

\section{Consent for publication}

All authors read and approved the final manuscript.

\section{Competing interests}

The authors declare that they have no competing interests.

Received: 30 August 2019 Accepted: 9 October 2019

Published online: 02 November 2019

\section{References}

1. Lerman J. Surgical and patient factors involved in postoperative nausea and vomiting. Br J Anaesth. 1992;69:24S-32S

2. Myles PS, Williams DL, Hendrata M, Anderson H, Weeks AM. Patient satisfaction after anaesthesia and surgery: results of a prospective survey of 10,811 patients. Br J Anaesth. 2000;84:6-10.

3. Parra-Sanchez I, Abdallah R, You J, Fu AZ, Grady M, Cummings K, et al. A time-motion economic analysis of postoperative nausea and vomiting in ambulatory surgery. Can J Anaesth. 2012:59:366-75.

4. Vari A, Gazzanelli S, Cavallaro G, De Toma G, Tarquini S, Guerra C, et al. Postoperative nausea and vomiting (PONV) after thyroid surgery: a prospective, randomized study comparing totally intravenous versus inhalational anesthetics. Am Surg. 2010;76:325-8.
5. Won YJ, Yoo JY, Chae YJ, Kim DH, Park SK, Cho HB, et al. The incidence of postoperative nausea and vomiting after thyroidectomy using three anaesthetic techniques. J Int Med Res. 2011;39:1834-42.

6. Yoo YC, Bai S-J, Lee KY, Shin S, Choi EK, Lee JW. Total intravenous anesthesia with propofol reduces postoperative nausea and vomiting in patients undergoing robot-assisted laparoscopic radical prostatectomy: a prospective randomized trial. Yonsei Med J. 2012;53:1197-202.

7. Gauger PG, Shanks A, Morris M, Greenfield MLVH, Burney RE, O'Reilly M. Propofol decreases early postoperative nausea and vomiting in patients undergoing thyroid and parathyroid operations. World J Surg. 2008;32:1525-34.

8. Visser K, Hassink EA, Bonsel GJ, Moen J, Kalkman CJ. Randomized controlled trial of total intravenous anesthesia with propofol versus inhalation anesthesia with isoflurane-nitrous oxide: postoperative nausea with vomiting and economic analysis. Anesthesiology. 2001;95:616-26.

9. Schumacher PM, Dossche J, Mortier EP, Luginbuehl M, Bouillon TW, Struys MMRF. Response surface modeling of the interaction between propofol and sevoflurane. Anesthesiology. 2009;111:790-804.

10. Diz JC, Del Rio R, Lamas A, Mendoza M, Duran M, Ferreira LM. Analysis of pharmacodynamic interaction of sevoflurane and propofol on Bispectral Index during general anaesthesia using a response surface model. $\mathrm{Br}$ J Anaesth. 2010;104:733-9.

11. Tramèr M, Moore A, McQuay H. Meta-analytic comparison of prophylactic antiemetic efficacy for postoperative nausea and vomiting: propofol anaesthesia vs omitting nitrous oxide vs total i.v. anaesthesia with propofol. Br J Anaesth. 1997;78:256-9.

12. Djalali AG, Sadovnikoff N. Cardioprotective properties of sevoflurane in patients undergoing coronary surgery with cardiopulmonary bypass are related to the modalities of its administration. Anesthesiology. 2005;102: 699-700.

13. Guarracino F, Landoni G, Tritapepe L, Pompei F, Leoni A, Aletti G, et al. Myocardial damage prevented by volatile anesthetics: a multicenter randomized controlled study. J Cardiothorac Vasc Anesth. 2006;20:477-83.

14. Apfel CC, Läärä E, Koivuranta M, Greim CA, Roewer N. A simplified risk score for predicting postoperative nausea and vomiting: conclusions from crossvalidations between two centers. Anesthesiology. 1999;91:693-700.

15. Schnider TW, Minto CF, Gambús PL, Andresen C, Goodale DB, Shafer SL, et al. The influence of method of administration and covariates on the pharmacokinetics of propofol in adult volunteers. Anesthesiology. 1998;88:1170-82.

16. Kim SY, Kim JM, Lee JH, Song BM, Koo BN. Efficacy of intraoperative dexmedetomidine infusion on emergence agitation and quality of recovery after nasal surgery. Br J Anaesth. 2013;111:222-8.

17. Minogue SC, Ralph J, Lampa MJ. Laryngotracheal topicalization with lidocaine before intubation decreases the incidence of coughing on emergence from general anesthesia. Anesth Analg. 2004;99:1253-7.

18. Myles PS, Hunt JO, Nightingale CE, Fletcher $H$, Beh T, Tanil D, et al. Development and psychometric testing of a quality of recovery score after general anesthesia and surgery in adults. Anesth Analg. 1999;88:83-90.

19. Silva AC, O'Ryan F, Poor DB. Postoperative nausea and vomiting (PONV) after orthognathic surgery: a retrospective study and literature review. J Oral Maxillofac Surg. 2006;64:1385-97.

20. Liang C, Ding M, Du F, Cang J, Xue Z. Sevoflurane/propofol coadministration provides better recovery than sevoflurane in combined general/epidural anesthesia: a randomized clinical trial. J Anesth. 2014;28:721-6.

21. Kawano H, Ohshita N, Katome K, Kadota T, Kinoshita M, Matsuoka Y, et al. Effects of a novel method of anesthesia combining propofol and volatile anesthesia on the incidence of postoperative nausea and vomiting in patients undergoing laparoscopic gynecological surgery. Braz J Anesthesiol. 2016;66:12-8.

22. Gan TJ, Glass PS, Howell ST, Canada AT, Grant AP, Ginsberg B. Determination of plasma concentrations of propofol associated with $50 \%$ reduction in postoperative nausea. Anesthesiology. 1997:87:779-84.

23. Kim MH, Lee KY, Lee K-Y, Min B-S, Yoo YC. Maintaining optimal surgical conditions with low insufflation pressures is possible with deep neuromuscular blockade during laparoscopic colorectal surgery. Medicine (Baltimore). 2016;95:e2920-7.

\section{Publisher's Note}

Springer Nature remains neutral with regard to jurisdictional claims in published maps and institutional affiliations. 